\title{
Reputation as a Mechanism for Coping with the Contingency of Social Addressing
}

\author{
Jörg Räwel*
}

\begin{abstract}
The transformation towards a functional differentiation of society and the current emergence of social media have increased the importance of reputation, because persons have become comparable and contingently addressable throughout society. We examine both social media and China's emerging "social credit system" to determine whether and to what extent these developments point to the development of a symbolically generalized communication medium of reputation, respectively, to a social change from functional to individual differentiation.
\end{abstract}

Keywords: reputation, social media, social credit system, tinder, metoo debate, unconditional basic income

\section{Reputation als Mechanismus zur Bewältigung der Kontingenz sozialer Adressierung}

Zusammenfassung: Der Wandel hin zur funktionalen Differenzierung der Gesellschaft und aktuell das Aufkommen der sozialen Medien verstärkten die Bedeutung von Reputation, da Personen gesellschaftsweit vergleichbar und kontingent adressierbar wurden. Mit Blick auf soziale Medien und auf Chinas entstehendes «Sozialkreditsystem» wird diskutiert, ob diese Entwicklungen auf den Aufbau eines symbolisch generalisierten Kommunikationsmediums der Reputation hinweisen, bzw. einen gesellschaftlichen Wandel von funktionaler zur individuellen Differenzierung andeuten.

Schlüsselwörter: Reputation, soziale Medien, soziales Kreditsystem, Tinder, Metoo-Debatte, bedingungsloses Grundeinkommen

\section{Réputation en tant que mécanisme pour faire face à la contingence de l'adressage social}

Résumé: L'évolution vers une différenciation fonctionnelle de la société et l'émergence actuelle des médias sociaux ont accru l'importance de la réputation, à mesure que les gens devenaient comparables et adressables dans la société. En considérant les médias sociaux et l'émergence d'un «système de crédit socia» en Chine, nous discutons si ces développements indiquent la mise en place d'un médium de communication « réputation » symboliquement généralisé, ou vont dans la direction d'une transformation de la société allant d'une différenciation fonctionnelle vers une différenciation individuelle.

Mots-clés: réputation, médias sociaux, système de crédit social, tinder, débat Metoo, revenu de base inconditionnel

\footnotetext{
Unabhängiger Forscher, joerg.raewel@gmail.com
} 
50 years ago, Niklas Luhmann prophesied: "Increasing complexity will exacerbate the discrepancy between the respective requirements posed by selection and motivation, and it cannot be excluded, but can almost be expected, that, in the course of further development, a functional differentiation must also occur here, which will explode the multifunctional medium of reputation." (Luhmann 1991 [1970], 244; my own translation). Nowadays, we can empirically observe that, in a society that increasingly perceives itself as a "global village" (McLuhan and Powers 1989), reputation does indeed have a society-wide significance, an importance that exceeds individual functional systems. This has come about through the emergence of an infrastructure (the internet) that overspans functional systems, and through the social media that reinforce the need for selection and motivation by facilitating the comparison of organizational and personal addresses throughout society.

For example, the reputation ("number of stars") of organizations often plays a decisive role in the selection of hotels and restaurants (by using corresponding comparison platforms such as "TripAdvisor" or map services such as "Google maps"). The reputation of people and goods is also often decisive when choosing taxi drivers or short-term rentals of accommodation (via online brokerage services such as "Uber" or "Airbnb"), when buying goods (for example via "Amazon") or when using services. This is especially true since (recommendable?) companies (such as "Yelp") have become established, whose business model is, in itself, the comparison or recommendation of organizations, goods and services.

But it is not only in relation to organizations, services and goods that reputation is of increasing importance, but also with regard to personal addresses, as is shown by the social media. Communication through services such as Facebook, Instagram, Twitter, Snapchat etc. is also significantly motivated by the possibility of increasing the number of likes, retweets, "friends" and followers - all of them indicators indexing reputation and popularity. When recruiting personnel for companies, the "googleable" reputation of people - not least with regard to user profiles and how applicants communicate in the social media - is of increasing importance. ${ }^{2}$ The phenomenon of "influencers" shows that reputation is not only marketable, but can itself be exploited economically (Kilian 2017).

In approaching the phenomenon of reputation, we propose a more abstract conception of this social mechanism than is usually advanced. In addition, a brief historical summary will discuss the socially induced change in meaning associated with the concept of reputation, or in this sense: honor or character (2. The Form

1 I thank the anonymous reviewers for their valuable hints and helpful critical comments, which have certainly contributed to the improvement of the paper. I would like to thank Anja Welle and Stan Jones for English editing, and Philippe Marchand for French editing.

2 Illustrative: Michael Page (Recruitment Consultancy). How to use your online reputation to find a job. 
of Reputation). With a view to current circumstances, the relevance of reputation is first discussed in relation to those media of personal addressability that can be generated via the infrastructure of the internet (3. Social Media). The following section discusses whether reputation can possibly be understood as a developing medium of communication, which is symbolically generalized (4. Reputation as a symbolically generalized Medium of Communication?). Particular attention will be paid to the question of whether it might be possible for reputation to perform functions equivalent to money. Our conclusion then discusses the question whether the developments in China may lead us to expect a fundamental change in the form of the modern, functionally differentiated society (5. Conclusion: Towards an individually differentiated society?).

Obvious prerequisites for the comparability of social addresses, which makes reputation possible and necessary, are technical developments, which are often described unspecifically, using the catchword "digitisation" and applying it to society. More precisely, we can speak of the development of "technically generalized communication media". This definition denotes the society-wide, cross-functional use of the same or similar programs on the basis of user profiles, which are then themselves guaranteed to be similar or comparable by data collection using electronic forms. ${ }^{3}$

In this context, it is astonishing to observe how, within a very short time (Facebook, for example, was only founded in 2004), a technical generalization of these communication media has become established throughout all society. For example, Facebook has around 2 billion active users per month (a quarter of the world's population!); Instagram displays over 1 billion active users per month; the microblogging service, Twitter, has over 320 million monthly users (source: statista.com).

Social media, the technically generalized communication media, acquire their medial character through the fact that they function only on the basis of the largest possible number of similar elements - namely user profiles (cf. Räwel 2018). Therefore, basing this study on the theoretical distinction between medium and form is empirically justifiable. We accordingly, derive the theoretical premise for our explanations from the development of this distinction by Heider (1926) and on the sociologically fruitful elaboration of it by Luhmann (for instance 1995, 165 ff.; 1997, 190 ff.).

The theoretical approach based on the abstract distinction between medium and form makes it possible to compare social phenomena that are initially presumed to be disparate. We can, therefore, compare social media with a, supposedly, symbolically generalized communication medium of reputation and can do so on the basis of their technical generalization or medialization considered as functionally necessary.

3 See on a theory of the development of "technically generalized communication media", i. e. applications such as Facebook, Twitter, Instagram, LinkedIn, Räwel (2018, esp. 54-56). 
The phenomenon of the society-wide relevance of reputation demands a conceptual version, which takes into account the fact that reputation is now of overarching importance across functional systems (cf., however, with specific reference to the system of science: Luhmann 1991 [1970]). Correspondingly, the merely individual attribution of reputation to persons or organizations would be inadequate. ${ }^{4}$ What is characteristic of reputation is that it represents a solution to a problem and, as such, is used in the selection of different, but nevertheless comparable addresses. Reputation is the decisive factor in favoring this company when buying a car, and not that one; to invite this scientist and not that one to give a lecture to a company; choosing this credit institution over that one when financing a project; etc.

As already mentioned in the title, we will, therefore, posit reputation as a mechanism that makes it possible to cope with the contingency of social addressing. ${ }^{5}$ This initially presupposes the comparability of addresses. The reputations of car companies do not provide any decision-making aid when buying a bicycle. In this respect, reputation presupposes, for example, from an economic point of view, an orientation towards markets, which enables comparability, and thus only becomes a problem in modern times. It can then be observed, for example, that honest dealing by traders, rather than fraud, pays off (Smith 1997 [1766]). ${ }^{6}$

4 In this sense we refer for example to the following definition: "Reputation means [...] the public image that a person, institution, organisation or, more generally, a (collective) subject enjoys in the mid or long term and one that results from the diffusion of assertions about prestige to unknown third parties beyond the scope of personal social networks" (Eisenegger 2005, 24-25; my own translation). The non-specific reference to the public does not adequately indicate that the reputation of persons, institutions and organisations can only be determined in relation to other, comparable persons, institutions and organisations. See also Gotsi and Wilson 2001 or Voswinkel 2011 as examples of many studies that attribute reputation individually.

5 The striking proximity of our concept to Luhmann's understanding of trust as a mechanism for reducing social complexity (Luhmann 2014 [1968]) should come as no surprise. Trust also has a societal significance. Also characteristic of Luhmann is the abandonment of a merely individual attribution of trust towards subjects or actors (persons, institutions, organizations; ibid.: $56 \mathrm{ff}$.). In general, a development of Luhmann's research is discernible, a development which came to an end in the so-called "autopoietic turn". Here a complete emancipation of positions referring to action theory has taken place. In this respect, it is to be understood as editorially conditioned atavism: Luhmann 2017.

6 Voswinkel (2011) links Adam Smith's perspective with the assumption of a human need for recognition and esteem, which is arguably anthropologically determined. In consequence of this is that he unilaterally regards an individually attributable positive reputation as characteristic for reputation: "Reputation is one aspect of esteem. It designates a positive image that is acquired and conferred for a limited time and for a specific quality or achievement; it gives rise to influence and is capable of inspiring confidence." (Voswinkel 2011,35). This view is neither empirically tenable (when asked about people who, for example, have the reputation of being particularly cruel despots, it is easy to refer to Hitler, Stalin, Pol Pot, etc.), nor is it adequate for the pivotal function of reputation. Social orientation, in coping with the problem of the contingent addressing of individuals, results precisely from different, positive and negative values of reputation. 
The comparability of respectable persons, persons with (good) standing in the pre-modern era, was limited by their relativization to strata and classes and was also limited in that a personal attribution was always to be assumed. Persons, not institutions or organizations, could, or can, possess honor. The code of honor - and thus the comparability of the persons encompassed by these codes - changed with class and gender (Luhmann 1988b, 54; Moeglin 1995, 85). It was, therefore, possible to distinguish a noble honor from that of the other social classes (cf. Voswinkel 2001, 107 ff.; Eisenegger 2005, 25 ff.). Honor was achieved or maintained through acting honestly, which, in stratified forms of society, had a more serious (moral) significance than in modern society, where (as honesty) it is usually only a matter of acting in the sense of integrity in handling money and material assets, or merely of avoiding lies (Merriam-Webster).

The change of the societal form from stratification to functional differentiation is accompanied by an increasing comparability of addressability. In politics, for example, it was no longer possible to assume quasi-natural positions of power sanctioned by God or nobility. Rather, the citizenry or the people (now including women) present themselves as a medium of the same kind, namely buman elements, from which no element or cluster of elements, such as emperor, principality, nobility, could claim a self-evident, high-ranking position of power (cf. Luhmann 1997, $609 \mathrm{ff}$.). The solution to the problem under these (democratic) conditions is to enable a tight coupling of elements, assigning temporarily limited reputable positions of power, by election. Accordingly, an allotment of power positions occurs on the condition that the tight coupling can be converted back into a loose one (cf. Luhmann $(1995,165 \mathrm{ff}$.) on the theory of media formation).

A similar schematism is applied under the social conditions of functional differentiation in the field of economy. Here, in the inverse sense, the problem arises that producers or providers of goods and services can obtain a dominant position ("monopoly") and thus arbitrarily impose conditions on consumers of these goods and services. The solution here is then: comparable elements (producers, suppliers) in competition form a medium ("market"), in which forms of tight coupling (market power, reputation) can be imposed by purchase or purchase decisions. At best, antitrust authorities must ensure that forms of tight coupling do not solidify, that the medium ("market") remains fluid and that the basically loose coupling of the elements, and thus competition, is maintained. ${ }^{7}$

$7 \quad$ The success of this scheme leads to it being overestimated. In the efforts to "privatize" (business) areas, we often fail to consider that this scheme can only be successfully applied if a medium - i. e. a multitude of similar elements - can be constructed. Although the number of providers, for example in the public transport sector, may be multiplied, the underlying infrastructure, which is often dilapidated, is not (cf. for example Spelthahn 1994; Atzmüller and Hermann 2004). With a view to "globalisation", even nation-states, then absurdly also seen as similar elements that are, in principle, susceptible to bankruptcy, would be subject to this economic, competition-oriented scheme (cf. Genschel and Seelkopf 2015). If, on the other hand, this scheme or legitimizing procedure (cf. Luhmann 1983) itself lacks legitimacy, it can be expected that personal networks 
The media of addressability can, therefore, only be spoken of under the conditions of modern society, the condition of functional differentiation. ${ }^{8}$ In the following, we will see that, with the advent of the internet and the social media, the problem (or the possibilities for problem solving resulting from this fact) of contingent addressing of similar and comparable social addresses - addresses in their multitude as a medial substrate - is drastically intensified.

\section{Social Media}

There are only three criteria to be considered when designing media: the similarity of the elements must be taken into account, a multitude of these (loosely coupled) elements must be constructible and it must be possible to tightly couple the elements and to subsequently dissolve this coupling (cf. Luhmann 1995, $165 \mathrm{ff}$., on the theory of the media and its formation).

Internet-based social media ensure the uniformity of their elements - namely the "user profiles" - by recording user data via online forms. If the provider of a platform manages to create a large number of tightly couplable user profiles, nothing stands in the way of the successful use of the medium. ${ }^{9}$ The form of the tight coupling of the loosely coupled elements, such as the form of a message, through which communication can possibly be initiated, differs from medium to medium. Examples are "friend requests" (Facebook), subscribing to user profiles ("following") at the short message service, Twitter, or at the photo/video sharing platform, Instagram, different "swipes" of a picture, as in the case of the dating service, Tinder (cf. Räwel 2018 for a more detailed discussion of theory).

The complexity of coping with the contingency of social addressing is initially reduced simply by the fact that the user profiles are governed by a topic. In addition,

will gain in importance. Then the importance of connections will increase, and people with a good reputation become important, e.g. people who are known for procuring materials for building a house or can shorten the waiting time for a car (Diewald 1995).

8 The societal (as well as sociological) obsession with the concept of the individual (cf. Luhmann 1993) can probably also be understood by the modern constitution of persons/addresses as comparable elements. Humankind is then so to speak understood as a medium.

9 It is precisely the similarity of user profiles as media elements that enables "big data", i. e. a statistical exploitation of large amounts of data. The user profiles of social media such as Facebook, which to a certain extent "supervise" people's everyday lives can once again be used to distill large amounts of similar media elements. In other words, groups of people to whom a different reputation can be assigned according to specific statistical criteria - for example, swing voters, buyers with a preference for luxury items, people with a politically radical attitude, people with little purchasing power, etc. - which, in turn, makes it possible to influence these people in a targeted manner, for example through specific advertising or selected, opportune news. The influence of targeted advertising on purchasing decisions is understandably perceived as far less scandalous than the greater impact of the influence by political lobbying on election decisions, as the affair surrounding the public relation company "Cambridge Analytica" shows (see, for example, Granville 2018). 
the uniformity of the elements of a medium is, once again and more specifically, ensured. This is the case with, for example, dating sites for the initiation of love and partnership (Parship, eDarling, Match.com etc.), forums, such as travel partner exchanges to find partners for common interests, social media that are beneficial for building professional/business interests or networks (such as LinkedIn, XING), affair agencies (such as meet2cheat, C-date, Ashley Madison), etc.

The social medium, Tinder (cf. tinder.com), which is thematically directed at initiating erotic (or possibly also "serious") partnership, makes it paradigmatically clear how the tight coupling of elements (user profiles), and thus the coping with the contingency of social addressing, basically takes place. In fact, given the popularity of this smartphone app, hundreds of potential and contingently addressable users can be expected in large cities, depending on the search radius. The application is well suited to illustrate our theoretical explanations, because its functionality is relatively simple and efficient.

In order to create a user profile, it is only necessary to provide at least one photo, the age and gender of the user, and to specify within which distance the smartphone's location system is to be used for searching. The (potentially) tight coupling of the elements (user profiles) of the medium takes place on the smartphone by wiping ("swipe") the displayed image to the right ("interest") or to the left ("rejection"), or by pressing the corresponding buttons.

Communication in this application works as follows: an utterance (wipe right/wipe left) is distinguished from information ("I like/dislike your photo.") by a follow-up utterance (wipe right/wipe left) and can be understood in this way (see for this concept of communication Luhmann 1984, $191 \mathrm{ff}$.). Communication in this sense enables exactly four different forms of understanding: 1 . both users like each other (visually); 2. disinterest from both users; 3. this user is interested, that one not; 4. that user is interested, this one not. Users are only provided with address list 1. ("Matches") enabling chats. Communication (i. e. chats first) is thus made probable, or, respectively, the contingency of social addressing is handled, by making users' mutual interest explicit. In fact, the list of persons of mutual interest can be understood as a minimal form of mutual reputation of persons - here, at least, persons literally assure each other of their good image.

However, the problem may be that - especially with regard to people generally considered attractive - the possible multitudes of people of mutual interest ("matches") themselves represent a medium of similar and comparable elements. Their addressing is, thus, once again contingent, and it then has to be dealt with anew. In this case, coping with the contingency of addressing is not a problem, in that it would be difficult to initiate communication via chat. However, in view of the possible multitude of communicative alternatives of the (attractive) addressed person, the probability increases that an answer will not be provided during the chat. In view of this - highly probable - possibility, the app actually provides an 
instrument to perform the tight coupling in the meta-medium of mutual interest ("Matches"): "Super Likes", of which a maximum of one can be assigned per day.

When initiating communication between two specific (individual, physically present) persons (alter/ego), the problem of double contingency arises, which must be dealt with, in order for communication to take place (cf. Parsons et al. 1951; Luhmann 1984, $148 \mathrm{ff}$.). This is especially true in the initiation of what is highly personal communication in the sphere of love. In contrast, communication in the social media has a completely different disposition. Here, it is, at least initially, not a matter of communicating with specific persons, but of enabling communication per se, at the most under the auspices of a certain topic, initially independent of individual addressability. In this respect, it is to be expected that very different mechanisms enabling communication will be used. It must be expected that, with the advent of social media, conventional forms of the initiation of erotic/romantic (love) relationships will come under pressure (cf. Räwel 2018, 56 ff.)

If, according to cultural traditions as they might be practiced a few decades ago, a certain individual person is to be "conquered" - in a sense "normatively" - a cognitive style of observation is necessary in wooing this person. A high degree of empathy - the ability to observe an individual person very closely, so to speak - makes it possible to assess whether persistence is worthwhile, whether you are justified in not being discouraged prematurely by any resistance. In (traditional) flirting, it is a question of exploring playfully and with empathy whether resistance is meant seriously or is part of the "game" of attraction and rejection, whether "serious" resistance can at best be dissolved. The point is to find out whether a "no" is really a "no". A "no" can traditionally also be understood as an instrument to probe the seriousness of the purpose with which a relationship is initiated.

If erotic or romantic (love) relationships are established through social media (dating sites), we assume that the cognitive styles (normative or cognitive) to be applied become more differentiated. In the first place, the cognition of a supraindividual medium is about establishing a relationship with an individual at all. People have to learn here that communication with this person may suddenly break off, but can still be continued with that person; this person is out of the question after a "face-to-face" meeting, but a meeting with another person is still pending; this person is out of the question after months of chat because he or she is married, so perhaps contact with that person should be re-established.

In view of the contingency of social addressing, and of the (seeming) multitude of alternatives, a traditional "conquest", an action that is not discouraged prematurely by "resistance", must appear as impertinence, as disrespect - even as an affront. Given the novelty of the social media, persons probably have yet to learn that a cognitive style of observation is now required in the beginning, with the selection from a multitude of people. On the other hand, a normative cognitive style tends to 
be more necessary in getting to know someone personally ("No means No"). ${ }^{10}$ But especially in the field of social media, with its unmanageable number of addresses, the problem naturally arises as to how sincerely a "serious" relationship is aimed for. Nevertheless, in view of the apparent multitude of alternative addresses in the social media (here specifically: dating agencies), we can assume a decreasing willingness to accept persons, who, despite signals of rejection, persistently (impertinently?) want to hold on to an emerging relationship in the sense of a traditional "conquest".

While empathy and tact (cf. Luhmann 1996) help to manage the problem of double contingency between individual persons (alter/ego), reputation can be understood as a mechanism that has become increasingly important in recent years, given the social media, to cope with the contingency of social addressing. A newly emerging communication medium cannot replace previously dominant forms of communication - just as book printing has not displaced oral forms of communication. Nevertheless, considerable social consequences must be expected, whose extent, however, in view of the novelty of the social media, can, as yet, hardly be estimated.

The following section discusses the social consequences that could be expected if reputation were to acquire an even more dominant social function, in the sense of its symbolic generalization. In view of the novelty of the (technical) developments, the question of whether reputation could assume an equivalent function to money will be discussed in a speculative but theory-based framework.

\section{$4 \quad$ Reputation as a symbolically generalized Medium of Communication?}

The possibilities for evaluating persons, organizations and institutions are manifold and unmanageable. We began by mentioning comparison websites, indicating how these allow, for example, an evaluation of hotels and restaurants, of goods and services, e. g. of medical doctors. The social media also offer a variety of possibilities for indicating reputation. Every single contribution, every photo and video can be evaluated (for example by "likes"). The number of "friends" (Facebook), followers (Instagram, Twitter), and retweets can indicate the reputation, popularity, and social influence of individuals or organizations. ${ }^{11}$ This is in addition to traditional ways of labelling the reputation of persons or organizations, for example, in legal terms, by references affirming good repute or, in economic terms, as regards creditworthiness ("credit history").

10 In this respect, it can be assumed that the current "\#MeToo" debate (cf. the corresponding Wikipedia article) or "No means No" movement (cf. https://www.nomeansnoworldwide.org/) is not only an expression of increasing social equality of the sexes, but is also caused by the emergence of social media.

11 See Garcia et al. 2017 for a statistical evaluation of popularity, reputation and social influence with regard to the "Twitter Society". 
The diversity and incomparability of the sources of knowledge on reputation seemed, at least until recently, far from being coordinated, in the sense of a generalization of the symbolic content of this information. If there were no real promising efforts in China to establish a societal "Social Credit System" (for example: Denyer 2016; Hvistendahl 2017, Liang et al. 2018), in which the aim is to bring together the multitude of societal information sources relating to reputation to form a (symbolically generalized?) "scoring", the question that describes this section could find a simple answer, one, that is, in the negative.

In fact, however, the "Social Credit System" establishing itself in China (Meissner 2017) has already been implemented so concretely that there is hardly any abstract planning stage to speak of anymore: "In the past two years, the most important data platforms of the system for storing and exchanging data have been set up. Government agencies and commercial credit rating agencies have begun processing and evaluation. Despite bureaucratic and technical hurdles, the basic structures should be in place by 2020" (Meissner 2017, 2; my own translation). In this context, it should be pointed out that only the algorithmically supported and society-wide technical generalization of communication media makes the comparability of information sources possible and thus allows information to be bundled and scored in relation to individuals (persons and organizations).

The coordination of the most varied sources of information on reputation would affect both companies and private individuals and would have far-reaching consequences. "Credit points" could be accumulated, for example, by complying with government regulations such as tax payments, by meeting standards on environmental protection (emissions), energy saving, recycling, job and production safety, or taking into account quotas for vehicles with alternative engine systems. The number of social "credit points" achieved would then determine, for example, whether a company would have access to public procurement, could access public subsidies or funds, or whether it could issue bonds. Furthermore, the availability of credit, the intensity of government supervision, access to online retail platforms, or the type of transport accessible, such as high-speed trains (Meissner 2017, 3), could depend on the "credit points" achieved.

In what follows, we will try to offer a theoretical examination (empirical data being hardly available given the novelty of the developments) of the likelihood of a system or communication medium actually establishing itself in which the number of "credit points" or "reputation points" achieved would be associated with symbolically generalized information content. In principle, such a communication medium would have the same function as money. ${ }^{12}$ It would regulate access and availability to scarce goods - however, unlike money, it would do so in relation to specific social addresses (individuals and organizations). Reputation would amount

12 Cf. Luhmann $(1997,312 \mathrm{ff}$.) with regard to the theoretical foundations of symbolically generalized communication media, such as power, money, or truth. 
to an individually attributable currency and would allow certain individuals or organizations access to limited goods or services - or not. Examples, with a view to persons, would apply to certain (luxurious) residential areas, holiday trips, or, with regard to reputation, "expensive" restaurants, or, regarding organizations, access to subsidies or certain credit facilities.

The most obvious potential effect of such a communication medium is, therefore, that it could serve as a substitute for the traditional communication medium of money. This function gains in importance by dint of the fact that an unconditional basic income is currently being discussed with a view to the systematic loss of jobs through automation (e.g. Hohenleitner and Straubhaar 2008 or Franzmann 2010). ${ }^{13}$ We can assume that the problem of the - unlikely - tolerance for the transfer of ownership, which is overcome by money (cf. Luhmann 1988a), would be defused through the automation of production and services. In this respect, a communication medium of reputation could have the function of encouraging people to take on activities entailing diminished motivation, if an unconditional basic income were introduced. For example, "credit points" could be earned for voluntary activities. It would also be possible to give certain activities, such as care for the elderly or the sick, housework, caring for children, acting in the interests of environmental protection, etc., a high degree of reputation.

In general, it is to be expected that a symbolically generalized communication medium of reputation would strengthen political influence. This can be illustrated, for example, with regard to tax avoidance strategies of globally active companies. It is currently absolutely legal for multinational companies to play off one nation's regulations on company and profit taxation against another's and thus reduce their tax burdens to a minimum or avoid them entirely (e. g. Overesch 2016). In response to these strategies, it would be unrealistic to hope that global coordination or harmonization of national tax legislation could be achieved, at least in the short term. It is probably more realistic to insist a company's reputation be included in its business dealings. This would be the case, if reputation, in its symbolic generalized meaning, were associated with consequences, for example, with regard to the sales of a company's products, or access to subsidies or funding, which can be controlled at national level.

With reputation as a symbolically generalized medium of communication, politics would have an instrument for steering certain actions (nursing care for the sick and the elderly, voluntary activities, energy-saving actions, household work, child care, compliance with taxation, avoiding the waste of energy, as mentioned above) below the threshold of criminalization. The danger or risk is that the stronger political influence concomitant on a symbolically generalized medium of communication of reputation would not be used in the public interest and in a

13 Between 20 and $50 \%$ of jobs, depending of course also on the particular field of work, should be endangered by automation (cf. e.g. Frey and Osborne 2017 or Rentmeister et al. 2017). 
democratically controlled manner, but that influence would itself merely serve to strengthen political power. In that case, monitoring and control possibilities would come to the fore, for example to target and eliminate or discredit political opponents.

In this context, it would be necessary for the political system, i. e. the reputable side of power (government), not to be exempt from evaluation of its (symbolically generalized) reputation (see also section 5 below). After all, it would be a democratic obligation on any government to not only allow the opposition to gain the reputable side of governing power, but to ensure that the criteria by which reputation ("credit points") can be acquired be also subject to democratic control. It is quite conceivable, for example, that there could be a democratic vote on whether tax avoidance strategies should be combined with massive reputational losses, or whether less formally reputable or less lucrative activities, such as nursing care for the sick and the elderly, or childcare, would be upvalued. ${ }^{14}$

The form of the medium, the way its elements are tightly coupled, differentiates fundamentally between money and reputation as symbolically generalized communication media. Both media would have to be understood as social currencies allowing access to scarce goods and services and control over them. While, however, the generation of forms in the medium of money takes place anonymously via the payment of certain expectation-forming prices (Luhmann 1988a, $230 \mathrm{ff}$.), the formation (a certain number of "credit points") in the medium of reputation would be directly linked to certain social addresses (persons and organizations). On the one hand, it is quite plausible to state that "money has no smell", by dint of the fact that money itself never reveals whether it was gained through tax evasion or tax avoidance, robbery and theft, drug deals etc. This is precisely why it can be "laundered". On the other hand, however, it must be noted that reputation as a social currency could certainly "smell".

In this respect, reputation as a symbolically generalized medium of communication is in danger of being confused with categories of morality. People with low "reputation values" could be disregarded as "entire human beings" and would, at worst, be affected by exclusion. ${ }^{15}$ "The possibility available for claiming, or expressing, respect or disrespect is a highly diffuse one. The form of this medium [morality, J. R.] only sets itself apart by the fact that it is not about the recognition

14 With a view to the criteria with which reputation can be acquired, it is easy to conceive of dystopias. For example, if only friendliness and a winning, agreeable appearance (and at best, attractiveness promoting agreeableness) in personal interactions were the only criterion with which reputation could be achieved, the possibility to "run amok" from time to time in interaction systems would almost be understood as utopian action. This contingency amusingly illustrates an episode from the Netflix series "Black Mirror" (Nosedive, Season 3, No. 1).

15 Misconduct that is linked to morality can, therefore, have far-reaching consequences. Thus, the actor Kevin Spacey, after accusations of sexual harassment became public against him, is not only legally responsible for these acts, but is also specifically excluded with regard to his artistic work - namely cut out of an already finished film (cf. Brown 2017). In this respect, we can also see that Luhmann was entirely justified in giving ethics the task of issuing warnings about morality (Luhmann and Spaemann 1990, 41). 
of the special skills or achievements of specialists, but about the inclusion of people, as they are, in societal communication." (Luhmann 1997, 397; my own translation)

However, in this context, it must be noted that, in view of its central position in modern society, money also can readily trigger social exclusion: The "de facto exclusion from a functional system - no work, no income, no identity card, no stable intimate relationships, no access to contracts and judicial protection, no possibility to distinguish political election campaigns from carnival events, illiteracy and medical and nutritional undersupply - limits what can be achieved in other systems and defines more or less large parts of the population, which are then often separated out in housing and thus made invisible." (Luhmann 1997, 630-631; my own translation)

Depending on the criteria by which reputation can be acquired, it may well be that, under the conditions of an established, symbolically generalized communication medium of reputation, the risk of (moral) exclusion is mitigated by assigning a certain "value of creditworthiness" to each person depending on his or her actions. The risks and difficulties in acquiring reputation would, therefore, - as with money - be generally known and could lead to low reputations being judged with caution (from a moral point of view), and without sanctioning exclusion. Just as poverty, in relation to the communication medium of money, is, at least cautiously, assessed in terms of morality.

On the contrary, the symbolically generalized communication medium of money, which allows anonymity, is associated with a double risk. On the one hand, there is the danger of including (legally and morally) fallible persons, such as thieves, drug traffickers, tax evaders or tax avoiders, profiteers of illegal gambling or illegal prostitution, who can certainly be well endowed with reputation, and that also from a legal point of view. On the other hand, there is a relatively high probability that persons who are legally (and, at best, morally) unencumbered, such as the unemployed, precariously employed, persons working in the low-wage sector, welfare beneficiaries, single parents, would be excluded from society.

However, it is difficult to imagine how reputation could take over the exchange and billing function of money in the transfer of ownership of goods between individual persons or organizations. But it should be emphasized once again that the problem of the improbable transfer of ownership weakens with increasing automation of production and work performance (or, more precisely, is at first intensified by rising unemployment rates). Precisely for this reason, in view of the current transformations of the "performance society", there is a need to consider alternative "payment options", such as reputation. 


\section{Conclusion: Towards an individually differentiated society?}

The current developments in China can provide indications of how the nomen nominandum of the "next society" (Baecker 2007) could be concretized.

The evolution of social formations is often associated with the potential effects from available communication media. Merely oral communication would thus enable a segmented differentiation of society, whereas social stratification is only realized through the second coding of language by writing. And subsequently, the functional differentiation of the social system is probably made possible by the mass distribution of writing that printing allows (cf. Havelock 1963; Luhmann 1981; Baecker 2007; Ong 2016 [1982]).

In order to get an idea of the social consequences that the technical generalization of communication media could have, it is first necessary to take a closer look at what basic abilities to discriminate of the different communication media possess. Which possibilities of differentiation can become plausible and on the basis of which similarities? On the basis of which commonplaces, certainties, do communication media render difference, otherness plausible? What follows is necessarily speculative and sketchy, due to a lack of any database for segmental forms of society functioning on the basis of oral communication.

Operational immediacy is characteristic of oral communication. Time, a recourse to the past, an anticipation of the future, is hardly available in the immediate presence of this communication (Ong 2016 [1982], 29 ff.). In one sense, the mode of oral communication promotes repeatability (traditions) and reflexes, not reflection and analysis, as these are time-consuming. Accordingly, an orientation towards simple (moral) schemes is preferred (such as friend/enemy, man/barbarian, own/ foreign), schemes that are characterized by a high sensitivity to dangers (deviations from the traditional) and allow tribes to maintain fast, defensive reactions (reflexes instead of reflections) to their inscrutable, threatening environments (empirical indications for this, for example, in Grierson 1903).

The invention of writing opens up the past and the future in a more complex way than merely through the traditions cultivated by oral communication. Temporal and spatial dimensions become available and can be experienced contingently (Bohn 2013, 44 ff.; Ong 2016 [1982], 91f). Strata (not least through the resulting distinction between literality and illiterality) can now be created, organized, and stabilized. The right to rule can be derived from the (written) past. The impetus of empires makes itself independent of space and time. Taxes and duties, for example, regulating ancient Egyptian stelae (cf. Erman and Wilcken 1900) will continue to have an effect in the future and in other places. Last but not least, the dimension of time gained through writing can be used to make the languages of previously threatening, incommensurable tribes comparable. The absoluteness of the distinc- 
tion between humans and barbarians becomes relative; potentially new dominions become available.

Letterpress printing, to a certain extent the popularization of textuality, finally made it possible to question the strata derived or demonstrated by means of textuality itself (the more so as progressive alphabetization dissolved the stratifying distinction between literacy and illiteracy). Book printing and the accompanying culture of the written word made possible and facilitated lasting (generation-spanning!) and thorough criticism of prevailing traditions and (then outdated) distinctions (strata). In a way, a "dissent tolerance" could be established (Bohn 2013, 89 ff.; see also Stichweh 1987).

Not the least effect was, then, that the "concept of man was generalized" (Luhmann 1997, 301; my own translation). Only the idea of the fundamental lack of difference of all human beings (including women, cf. Luhmann 1988b, $53 \mathrm{ff}$.), proclaimed for instance in the "Virginia Declaration of Rights" of 1776, makes the social orientation towards different functions (such as politics, economy, science, art) possible and necessary. The different professions now accessible to all people are no longer hierarchically connoted; although differences concerning social prestige remain discernible.

This, admittedly, very rough sketch is intended to prepare the ground for discussing the question that interests us, which social effects can be expected with regard to the newly developed electronic communication media. Technical generalization - i. e. the use of similar programs (or "apps") across society and functional systems - is based on user profiles and allows, related to individuals, an algorithmically supported comparison of functionally different forms of communication. It is possible, at present primarily with the help of smartphones, to aggregate different functional forms of communication and make them comparable in relation to individuals - concretely: user profiles. For example, communication concerning the economy (in the use of internet banking), politics (e.g. the communication of election preferences in corresponding social media), love (in the use of online dating websites), communication concerning sports activities through the use of fitness apps, artistic preferences in the favouring of specific music streams or the purchase of varying theatre or cinema tickets and so on, can be made comparable in relations to individuals (user profiles). As shown in reference to reputation, individual key indicators related to persons or organizations can transcend the communication of functional systems to the extent that they can be understood as aggregates across functional systems.

Just as the "generalization" of humans, which only made comparability possible, allowed a social differentiation in orientation to different functions (political, economic, scientific, educational, etc.), only the algorithmically driven comparison of communication between functional systems, made possible by technical generalization, allows a differentiation on the level of individuals (persons and organizations). 
In short, as the developments in China illustrate, technical generalization in principle permits the evolution of an individually differentiated society, e. g. according to the parameter of reputation. Other parameters that enable individual differentiation are, for example, security risks or the buying interests of persons or organizations. The NSA's "Prism" monitoring programme (cf. Greenwald and MacAskill 2013 or Gellman and Poitras 2013) or social media such as Facebook (cf. Carter-Harris et al. 2016) show that here too we can no longer speak of merely theoretical possibilities. In fact, the algorithmic determination of individual buying interests, which enables targeted advertising, is currently the main business model of social media.

Whether or not technical innovations are used to establish a totalitarian control and surveillance state - as expressed in current fears about China - is a contingency that depends on whether or not the political system itself makes itself accessible to what would then have to be democratic surveillance, based, for example, on an individual differentiation of politicians by their reputation. In principle, at any rate, technical developments would also make it possible to strengthen democratic control. It would be conceivable, for example, to observe the communication of political intentions (e.g. in social media), aggregate them algorithmically and permanently take them into account politically, on a real-time basis. Such a technocratic democracy (or: democratic technocracy?) would make a periodic election obsolete and would have the advantage of strengthening democracy by also taking into account the political expressions of will by so-called nonvoters (an increasing problem in democracies).

Despite other problems in establishing a "liquid democracy" (cf. Blum and Zuber 2016), these optimistic assessments cannot, however, blind us to the fact that the possibilities of technically generalized communication media are currently and de facto being "hijacked" politically in China. In other words, the potential for control and surveillance that these media also offer serves instrumentally and undemocratically to strengthen political power (cf. Liang et al. 2018). ${ }^{16}$

The institutionalized heterarchy of two perspectives - government and opposition - regarding legitimacy enables control and limitation of political power. This is achieved by oscillating between these perspectives in a democratic way, which also reflexively generates political insights (Luhmann 2000, $164 \mathrm{ff}$.). At the level of the system of society, this constellation is dependent on the heterarchical multiperspectivity of functionally differentiated systems. One can think here primarily of an independent system of justice or independent mass media. This is in addition to the multi-perspectivity, which results, for example, from science, education, art, or religion and serves to restrict domination and reflexively generate knowledge.

Money and reputation can also be compared (see Section 4) to the extent that both, in their significance across functional systems, can have potentially eroding

16 This also raises the question of whether cultural peculiarities in China favor politically authoritarian tendencies (cf. Fukuyama 1995 or Hu 1997). 
effects on the form of the functionally and heterarchically differentiated society existing at present: with regard to reputation, as described above with reference to China, through a society-wide penetration with technically generalized communication media: with respect to money, mainly in the constellation of a fully developed, global economic system that contrasts with a policy nevertheless fragmented along national lines. At the least, this tension entails the risk of sovereign tasks, such as tax legislation, being economically corrupted. Taxes, similar to the fixing of prices, are therefore subject to economic competition (see specifically Genschel and Seelkopf 2015, and, in more general terms, Strange 1996; see also footnote 7 above).

Given the novelty of these developments, it is difficult to predict the (negative) consequences that social penetration with technically generalized communication media will actually have in the long term. It should be emphasized, however, that all attempts so far to establish a dominant (political) perspective, which, in its corrupting impetus, would pose a threat to the primary, multi-perspectival form of differentiation of modern society, have quickly proved to be unstable. For example, the ideology dressed up as "socialism" in the Soviet Union resulted in a politically controlled economy (planned economy), party political control of the justice system, politically controlled "socialist" art and education, politically censored mass media, or a ban on religion (cf. Hosking 1993).

In this respect, we can hardly assume that technical generalization could result in the dissolution of functional differentiation. This is just as unlikely as segmentation or stratification, as forms of differentiation, becoming obsolete in the face of functional differentiation. Whether an "individually differentiated society" can grow into the primary social form of differentiation (as is currently the case with functional differentiation) remains uncertain in view of the novelty of the development of technical communication media. Currently, a meta-medium of symbolically generalized reputation in world society appears to have the function of mediating between functional systems. At present, at any rate, a medium of reputation in a complex world society probably has the complexity-reducing function of trust (cf. Luhmann 2014). In the last analysis, trust seems, in fact, to be a mechanism that has been more trusted in relation to the circumstances prevailing in nation-states.

\section{References}

Atzmüller, Roland, and Christoph Hermann. 2004. Veränderung öffentlicher Beschäftigung im Prozess der Liberalisierung und Privatisierung. Österreichische Zeitschrift für Soziologie 29(4): 30-48.

Baecker, Dirk. 2007. Studien zur nächsten Gesellschaft. Frankfurt a. M.: Suhrkamp.

Black Mirror (Netflix-Series). Nosedive. Season 3, No. 1.

Blum, Christian, and Christina Isabel Zuber. 2016. Liquid Democracy: Potentials, Problems, and Perspectives. Journal of Political Philosophy 24 (2): 162-182. 
Bohn, Cornelia. 2013. Schriftlichkeit und Gesellschaft: Kommunikation und Sozialität der Neuzeit. Wiesbaden: Springer-Verlag.

Brown, Mark. 9.11.2017. Kevin Spacey Cut Out of Film and Replaced by Christopher Plummer. The Guardian, https://www.theguardian.com/culture/2017/nov/09/kevin-spacey-cut-out-of-filmand-replaced-by-christopher-plummer (27.05.2019).

Carter-Harries, Lisa, Rebecca Bartlett Ellies, Adam Warrick and Susan Rawl. 2016. Beyond Traditional Newspaper Advertisement: Leveraging Facebook-Targeted Advertisement to Recruit Long-Term Smokers for Research. Journal of Medical Internet Research 18(6): e117, https://www.ncbi.nlm. nih.go v/pmc/articles/PMC4927805/ (27.05.2019)

Denyer, Simone. 22.10.2016. China Wants to Give All of its Citizens a Score - And Their Rating Could Affect Every Area of Their Lives. Independent, https://www.independent.co.uk/news/world/asia/ china-surveillance-big-data-score-censorship-a7375221.html (27.05.2019).

Diewald, Martin. 1995. «Kollektiv», «Vitamin B» oder Nische. Persönliche Netzwerke in der DDR. Pp. 223-260 in Kollektiv und Eigensinn. Lebensverläufe in der DDR und danach, edited by Johannes Huinink and Karl U. Mayer. Berlin: Akademie Verlag.

Eisenegger, Mark. 2005. Reputation in der Mediengesellschaft Konstitution. Issues Monitoring. Issues Management. Dissertation, Soziologie, Universität Zürich. Wiesbaden: VS Verlag,

Erman, Adolf, and Ulrich Wilcken. 1900. Die Naukratisstele. Zeitschrift für Ägyptische Sprache und Altertumskunde 38(1): 127-133.

Frey, Carl B., and Michael A. Osborne. 2017. The Future of Employment: How Susceptible are Jobs to Computerisation? Technological forecasting and social change 114: 254-280.

Franzmann, Manuel. 2010. Bedingungsloses Grundeinkommen als Antwort auf die Krise der Arbeitsgesellschaft. Weilerswist: Velbrück.

Fukuyama, Francis. 1995. Confucianism and Democracy. Journal of Democracy 6(2): 20-33.

Gellman, Barton, and Laura Poitras. 6.06.3013. US Intelligence Mining Data from Nine U.S. Internet Companies in Broad Secret Program. The Washington Post, https://wapo.st/2QJKcos (27.05.2019).

Genschel, Philipp, and Laura Seelkopf. 2015. The Competition State: The Modern State in a Global Economy. Pp. 237-252 in The Oxford Handbook of Transformations of the State, edited by Stephan Leibfried, Evelyne Huber, Matthew Lange, Jonah D. Levy and John D. Stephens. Oxford: Oxford University Press.

Greenwald, Glenn and Ewen MacAskill. 7.06.2013. NSA Prism Program Taps in to User Data of Apple, Google and Others. The Guardian, https://www.theguardian.com/world/2013/jun/06/us-techgiants-nsa-data (27.05.2019).

Garcia, David, Pavlin Mavrodiev, Daniele Casati and Frank Schweitzer. 2017. Understanding Popularity, Reputation, and Social Influence in the Twitter Society. Policy \& Internet 9(3): 343-364.

Gotsi, Manto and Alan M. Wilson. 2001. Corporate Reputation: Seeking a Definition. Corporate Communications: An International Journal 6(1): 24-30.

Granville, Kevin. 19.03.2018. Facebook and Cambridge Analytica: What you need to know as fallout widens. The New York Times, https://www.nytimes.com/2018/03/19/technology/facebook-cambridge-analytica-explained.html (27.05.2019).

Grierson, Philip J. H. 1903. The Silent Trade. A Contribution to Early History of Human Intercourse. Edinburgh: William Green \& Sons.

Havelock, Eric A. 1963. Preface to Plato. Cambridge: Harvard University Press.

Heider, Fritz. 1926. Ding und Medium. Symposium 1(2): 109-157.

Hohenleitner, Ingrid, and Thomas Straubhaar. 2008. Bedingungsloses Grundeinkommen und Solidarisches Bürgergeld - mehr als sozialutopische Konzepte. Pp.9-127 in Bedingungsloses Grundeinkommen und Solidarisches Bürgergeld - mehr als sozialutopische Konzepte, edited by Thomas Straubhaar. Hamburg: Hamburg University Press. 
Hosking, Geoffrey A. 1993. The First Socialist Society: A History of the Soviet Union From Within. Harvard: Harvard University Press.

Hu, Shaohua. 1997. Confucianism and Western Democracy. Journal of Contemporary China 6(15): 347-363.

Hvistendahl, Mara. 14.12.2017. Inside China’s Vast New Experiment in Social Ranking. Wired, https:// www.wired.com/story/age-of-social-credit/ (27.05.2019).

Kilian, Karsten. 2017. Influencer Marketing - Markenerfolg mit reichweitenstarken prominenten Testimonials. transfer Werbeforschung \& Praxis 63(2): 60-66, http://www.markenlexikon.com/texte/ transfer_kilian_influencer-marketing_2_juni2017.pdf.

Liang, Fan, Vishnupriya Das, Nadiya Kostyuk, and Muzammil M. Hussain. 2018. Constructing a Data Driven Society: China's Social Credit System as a State Surveillance Infrastructure. Policy \& Internet 10(4): 415-453.

Luhmann, Niklas. 1981. Geschichte als Prozess und die Theorie sozio-kultureller Evolution. Pp. 178-197 in Soziologische Aufklärung 2, edited by Niklas Luhmann. Opladen: Westdeutscher Verlag.

Luhmann, Niklas. 1983. Legitimation durch Verfahren. Frankfurt/M.: Suhrkamp.

Luhmann, Niklas. 1984. Soziale Systeme. Frankfurt/M.: Suhrkamp.

Luhmann, Niklas. 1988a. Die Wirtschaft der Gesellschaft. Frankfurt/M.: Suhrkamp.

Luhmann, Niklas. 1988b. Frauen, Männer und George Spencer Brown. Zeitschrift für Soziologie 17(1): 47-71.Luhmann, Niklas. 1991 [1970]. Selbststeuerung der Wissenschaft. Pp. 232-252 in Soziologische Aufklärung 1, edited by Niklas Luhmann. Opladen: Westdeutscher Verlag.

Luhmann, Niklas. 1993 [1989]. Individuum, Individualität, Individualismus. Pp. 149-258 in Gesellschaftsstruktur und Semantik: Studien zur Wissenssoziologie der modernen Gesellschaft Bd.3., edited by Niklas Luhmann. Frankfurt/M.: Suhrkamp.

Luhmann, Niklas. 1995. Die Kunst der Gesellschaft. Frankfurt/M.: Suhrkamp.

Luhmann, Niklas. 1996. Takt und Zensur im Erziehungssystem. Pp. 279-294 in Zwischen System und Umwelt. Fragen an die Pädagogik, edited by Niklas Luhmann and Karl E. Schorr. Frankfurt/M.: Suhrkamp.

Luhmann, Niklas. 1997. Die Gesellschaft der Gesellschaft. Frankfurt/M.: Suhrkamp.

Luhmann, Niklas. 2000. Die Politik der Gesellschaft. Frankfurt/M.: Suhrkamp.

Luhmann, Niklas. 2014 [1968]. Vertrauen. Ein Mechanismus der Reduktion sozialer Komplexität. Stuttgart: UTB GmbH.

Luhmann, Niklas. 2017. Systemtheorie der Gesellschaft. Frankfurt/M.: Suhrkamp.

McLuhan, Marshall, and Bruce R. Powers. 1989. The Global Village: Transformations in World Life and Media in the $21^{s t}$ Century. New York: Oxford University Press.

Luhmann, Niklas, and Robert Spaemann. 1990. Paradigm Lost: ̈̈ber die ethische Reflexion der Moral: Rede anlässlich der Verleihung des Hegel-Preises 1989. Frankfurt/M.: Suhrkamp.

Me Too movement (Wikipedia Article), https://en.wikipedia.org/wiki/Me_Too_movement (19.06.2019).

Meissner, Mirjam. 3.08.2017. Chinas gesellschaftliches Bonitätssystem. Marktregulierung mit Hilfe von Big Data hat weitreichende Folgen für Unternehmen in China. Merics China Monitor, Mercator Institute for China Studies (MERICS), https://www.merics.org/de/microsite/china-monitor/ chinas-gesellschaftliches-bonitaetssystem (27.05.2019).

Michael Page (Recruitment Consultancy). 2019. How to use your online reputation to find a job, https:// www.michaelpage.ch/advice/career-advice/job-search-advice/how-use-your-online-reputationfind-job (19.06.2019).

Moeglin, Jean-Marie. 1995. Fürstliche Ehre und verletzte Ehre der Fürsten im spätmittelalterlichen deutschen Reich. Pp.77-91 in Verletzte Ehre. Ehrkonflikte in Gesellschaften des Mittelalters und 
der frühen Neuzeit, edited by Klaus Schreiner and Gerd Schwerhoff. Köln, Weimar, Wien: Böhlau Verlag.

No Means No Worldwide (Global Rape Prevention Organization), https://www.nomeansnoworldwide. org (19.06.2019).

Ong, Walter J. 2016 [1982]. Oralität und Literalität: Die Technologisierung des Wortes. Wiesbaden: Springer VS.

Overesch, Michael. 2016. Steuervermeidung multinationaler Unternehmen. Die Befunde der empirischen Forschung. Perspektiven der Wirtschaftspolitik 17(2): 129-143.

Parsons, Talcott, Edward A. Shils, and James Olds. 1951. Categories of the Orientation and Organization of Action. Pp. 53-109 in Towards a General Theory of Action, edited by Talcott Parsons and Edward A. Shils. Cambridge: Harvard University Press.

Räwel, Jörg. 2018. Technisch generalisierte Kommunikationsmedien. Kommunikation im Medium der Adresslisten. Studies in Communication Sciences 18(1): 41-66.

Stichweh, Rudolf. 1987. Die Autopoiesis der Wissenschaft. Pp. 447-481 in Theorie als Passion, edited by Dirk Baecker. Frankfurt/M.: Suhrkamp.

Strange, Susan. 1996. The Retreat of the State: The Diffusion of Power in the World Economy. Cambridge: Cambridge University Press.

Rentmeister, Heinrich, Andreas Jentzsch, Patrick Bauer, Tim Arnold de Almeida, and Danyal Bayaz. 2017. Schöne neue Arbeitswelt 4.0? Was wir tun müssen, damit uns die Arbeit nicht ausgeht. Düsseldorf: Boston Consulting Group, https://tinyurl.com/y2gtelcb (19.06.2019).

Smith, Adam. 1997 [1766]. Lecture on the Influence of Commerce on Manners. Pp. 17-20 in Reputation: Studies in the Voluntary Elicitation of Good Conduct, edited by Daniel B. Klein. Ann Arbor: University of Michigan Press.

Spelthahn, Sabine. 1994. Privatisierung natürlicher Monopole. Theorie und internationale Praxis am Beispiel Wasser und Abwasser. Wiesbaden: Gabler Verlag.

Voswinkel, Stephan. 2001. Anerkennung und Reputation. Die Dramaturgie industrieller Beziehungen. Konstanz: UVK Verlag.

Voswinkel, Stephan. 2011. Reputation: A Sociological View. Pp. 31-45 in Reputation Management, edited by Sabrina Helm, Kerstin Liehrs-Gobbers, Christopher Storck. Berlin, Heidelberg: Springer. 